Industrial Health, 1983, 21, 25-34.

\title{
On the Biological Half-Time of Hexavalent Chromium in Rats
}

\author{
Seiya YAMAGUCHI, Ken-ichi SANO and \\ Nobuhiro SHIMOJO \\ Institute of Community Medicine, The University of Tsukuba, \\ Sakura-mura, Niihari-gun, Ibaraki 305, Japan
}

(Received September 28, 1982 and in revised form November 15, 1982)

\begin{abstract}
In this 30-day study, the distribution and excretion, and the biological half-time (B.H.T.) of chromium in selected organs of the rat were studied and the results obtained showed a characteristic difference between hexavalent $(\mathrm{Cr} \mathrm{VI})$ and trivalent (Cr III) chromium compounds.

The rate of retention at the site of a single injection of $\mathrm{Cr}$ III was 88.7\% (after $24 \mathrm{hrs}$ ) whereas that of $\mathrm{Cr}$ VI was 6.4\%. After the administration of $\mathrm{Cr} \mathrm{VI}, 232.73$ $\mu \mathrm{g}$ or $36 \%$ of the total chromium injected was excreted into the urine within 7 days while $48.45 \mu \mathrm{g}$ or $8.0 \%$ was excreted after Cr III administration. The amount of chromium excreted in the feces within 7 days after the injection of Cr VI was $89.17 \mu \mathrm{g}$ or $13.9 \%$, while the amount of chromium excreted was $146.96 \mu \mathrm{g}$ or $24.2 \%$ of the Cr III administered.

The results of calculation of B.H.T. in several organs after a single administration of $\mathrm{Cr}$ VI were as follows. The lung showed two components represented by two kinds of regression lines. The calculated B.H.T. was 60.2 hours ( 2.5 days) and 501.6 hours (20.9 days). The liver showed three components, 2.4 hours, 52.8 hours and 376.2 hours (15.7 days); the kidney had two components, 52.8 hours and 250.8 hours (10.5 days); the brain also showed two components, 4.4 hours and 231.52 hours (9.6 days); the heart showed two components, 66.9 hours and 334.42 hours (13.9 days); the testis also showed two components, 4.58 hours and 300.9 hours (12.5 days); and the blood had only one component, 334.4 hours (13.9 days).
\end{abstract}

Key words : Biological Half-Time-Hexavalent chromium-Trivalent chromiumTGMA-Formula--Reticuloendothelial system

\section{INTRODUCTION}

A limited amount of information on the biological half-time of chromium compounds in the light of toxicology is available at the moment.

However studies on the toxicity, carcinogenicity or mutagenicity of chromium compounds will certainly require considerab'e established knowledge of the pharmacodynamics of the compounds including their uptake, elimination and 
retention .

The experiments reported in this paper were devoted mainly to disclosing the biological haif-time of chromium compounds. Their results will be utilized to clarify the difference in the toxicity of hexavalent and trivalent chromium.

\section{Materials ANd Methods}

Male Wistar JCL rats [age: 6 weeks, $134.7 \pm 4.5 \mathrm{~g}(\mathrm{~N}=42)$ b.w.] were kept for a week, five per cage, for the purpose of quarantine, then 32 healthy rats, including two controls, were selected for the study.

The body weight of the rats at the beginning of the experiment was $187.4 \pm$ $6.8 \mathrm{~g}$. The chromium compounds administered were $\mathrm{K}_{2} \mathrm{Cr}_{2} \mathrm{O}_{\overline{7}}(\mathrm{Cr} \mathrm{VI})$ and $\mathrm{Cr}\left(\mathrm{NO}_{3}\right)_{3}$ ( $\left.\mathrm{Cr} \mathrm{III}\right)$. Chromium nitrate was chosen because its solubility makes it effective for subdermal injection. The chemicals were dissolved in water and $5 \mathrm{mg} / \mathrm{Kg}$ (as $\mathrm{Cr}$ ) of each compound was injected once subcutaneously in the backs of rats.

After the injection, animals were sacrificed at 1, 3, 6, 9, 12 and 24 hours and $2,3,4,5,10,15,20,25$ and 30 days. The concentration of total chromium in various organs was determined and compared with that in the control rats. The organs selected were the brain, lungs, heart, liver, kidneys, spleen, testis, muscle and blood. Hair, urine and the feces were also tested.

\section{Determination of chromium in biological specimens}

\section{Procedure for digesting biological specimens}

A calculated amount of sample material is put into a Kjeldahl flask, $\mathrm{HNO}_{3}$ and $\mathrm{H}_{2} \mathrm{O}_{2}$ are added and the flask is heated gently. The organic material in the specimen is thus decomposed and the remaining liquid becomes transparent and colourless.

\section{Apparatus}

Determination of chromium was carried out by the flameless atomic absorption method using a carbon graphite tube atomizer. The apparatus and conditions for the measurement were as follows:

Equipment: Shimadzu model 640-01 atomic absorption with $\mathrm{D}_{2}$ background corrector, GFA2 flameless atomizer.

Light source: Hamamatsu TV, hollow cathode lamp.

Wave length: $357.9 \mathrm{~nm}$

Lamp current: $5 \mathrm{~mA}$

Slit: $\quad 3.8 \AA$

Drying: $18 \mathrm{~A} \quad 30 \mathrm{sec}$

Ashing: $80 \mathrm{~A} \quad 45 \mathrm{sec}$

Atomizing: $260 \mathrm{~A} 8 \mathrm{sec}$ 
Flow rate $(\mathrm{Ar}): \quad 3.0 \mathrm{~L} / \mathrm{min} \quad\left(0.5 \mathrm{Kg} / \mathrm{cm}^{2}\right)$

\section{Accuracy of the method}

The sensitivity and the accuracy of this method were evaluated. A known amount of chromium was added to a human urine samp.e and calibrated according to the respective concentration. The detectable limit by this method was $0.2 \times$ $10^{-5} \mu \mathrm{g}(\mathrm{Cr})(\mathrm{S} / \mathrm{N}=2)(\mathrm{N}$ : Noise $)$, and the recovery percentage was $98.5 \%$ for a standard solution and $92.2 \%$ for the urine sample. No disturbance was observed even when $\mathrm{Cu}, \mathrm{Zn}, \mathrm{Ni}, \mathrm{Pb}, \mathrm{As}$, or $\mathrm{Cd}$, at 200 times the $\mathrm{Cr}$ concentration $(5 \mathrm{mg} / \mathrm{L})$, were added to the test sample.

Sodium ion gave a slight interference when the amount added was 200 times the $\mathrm{Cr}$ concentration, but the mixture containing 100 times as much sodium ion as $\mathrm{Cr}$ caused no disturbance in the determination of $\mathrm{Cr}$.

It was concluded that the method employed in this experiment is accurate and adequately out resist to several disturbing contaminants.

\section{RESUlts}

\section{Excretion of chromium compounds}

The excretion of hexavalent and trivalent chromium was compared in rats kept in specially designed cages for the determination of metabolism. Table 1 shows urinary and fecal excretion of total chromium after a single injection of $\mathrm{Cr}$ VI. Urinary excretion of chromium increased markedly the day after the injection then gradually decreased until the 15 th day when only $0.6 \%$ of the administered chromium was eliminated.

Chromium was eliminated in the feces beginning the day after the injection, but the amount excreted was less than that eliminated in the urine.

Table 1. Urinary and fecal excretion of $\mathrm{Cr}$ after single injection of $\mathrm{K}_{2} \mathrm{Cr}_{2} \mathrm{O}_{7}$ ( $\mu$ g/day)

\begin{tabular}{cccccccccccc}
\hline $\begin{array}{c}\text { Amount of } \mathrm{Cr} \\
\text { administered }\end{array}$ & $\begin{array}{c}\text { Days after } \\
\text { injection }\end{array}$ & 0 & 1 & 2 & 3 & 4 & 5 & 6 & 7 & 11 & 15 \\
\hline $620 \mu \mathrm{g}$ & Urine & 0.23 & 142.29 & 33.43 & 15.77 & 11.70 & 8.70 & 9.43 & 7.31 & & \\
& Feces & 0.03 & 42.04 & 41.58 & 7.70 & 3.04 & & 5.29 & 3.35 & & \\
\hline $640 \mu \mathrm{g}$ & Urine & 0.25 & 145.96 & 34.45 & 15.78 & 13.34 & 10.57 & 10.50 & 9.45 & & \\
& Feces & 0.02 & 30.34 & 26.70 & 0.11 & 3.23 & 2.67 & & 2.02 & & \\
\hline $660 \mu \mathrm{g}$ & Urine & 0.05 & 141.82 & 36.62 & 14.99 & 11.68 & 7.36 & 8.62 & 7.81 & 3.24 & 3.92 \\
& Feces & 0.05 & 35.09 & 20.69 & 8.70 & 4.01 & 1.51 & 2.47 & 3.17 & 2.41 & 2.86 \\
\hline$\mu \mathrm{g}$ (mean) & Urine & 0.18 & 143.36 & 34.03 & 15.51 & 12.24 & 8.90 & 9.52 & 8.19 & 3.24 & 3.92 \\
& Feces & 0.03 & 30.49 & 29.68 & 0.20 & 3.69 & 2.09 & 3.88 & 3.11 & 2.41 & 2.86 \\
\hline$\%$ (mean) & Urine & 0.03 & 23.1 & 5.4 & 2.4 & 1.9 & 1.4 & 1.5 & 1.3 & 0.5 & 0.6 \\
& Feces & 0.005 & 6.0 & 4.6 & 1.2 & 0.6 & 0.3 & 0.6 & 0.5 & 0.4 & 0.5 \\
\hline
\end{tabular}


Table 2 shows the excretion of the chromium compound after a single injection of Cr III.

A large amount of chromium was excreted in the feces only one day after its administration, and then the amount decreased rapidly. The amount of chromium excreted in the urine was, in contrast, very small from the beginning; however the amount did not drastically decrease after that as was the case for fecal excretion.

Table 2. Urinary and fecal excretion of $\mathrm{Cr}$ after single injection of $\mathrm{Cr}\left(\mathrm{NO}_{3}\right)_{3}$ $(\mu \mathrm{g} / \mathbf{d a y})$

\begin{tabular}{lccccccccc}
$\begin{array}{c}\text { Amount of Cr } \\
\text { administered }\end{array}$ & $\begin{array}{c}\text { Days after } \\
\text { injection }\end{array}$ & 0 & 1 & 2 & 3 & 4 & 7 & 8 & 10 \\
\hline $605 \mu \mathrm{g}$ & Urine & 0.23 & 37.11 & 7.41 & & 4.91 & & 2.88 & 1.15 \\
& Feces & 0.03 & 122.16 & 3.808 & & 1.93 & & 2.66 & 0.62 \\
\hline $605 \mu \mathrm{g}$ & Urine & 0.25 & 28.59 & 5.68 & 4.47 & 6.56 & 2.64 & 1.80 & 1.07 \\
& Feces & 0.02 & 59.51 & 11.46 & 2.61 & 2.21 & 4.79 & 3.76 & 0.66 \\
\hline $600 \mu \mathrm{g}$ & Urine & 0.05 & 26.53 & 6.48 & 1.59 & 4.70 & 2.54 & 2.47 & 1.21 \\
& Feces & 0.05 & 203.13 & 9.50 & 2.97 & 3.12 & 3.59 & 3.43 & 0.88 \\
\hline$\mu \mathrm{g}$ (mean) & Urine & 0.18 & 30.74 & 6.52 & 3.03 & 5.39 & 2.59 & 2.35 & 1.14 \\
& Feces & 0.03 & 128.27 & 8.26 & 2.79 & 2.42 & 4.19 & 3.28 & 0.72 \\
$\%$ (mean) & Urine & 0.03 & 5.1 & 1.1 & 0.51 & 0.90 & 0.43 & 0.39 & 0.19 \\
& Feces & 0.005 & 21.38 & 1.38 & 0.47 & 0.40 & 0.70 & 0.55 & 0.12 \\
\hline
\end{tabular}

Table 3. Concentration of $\mathrm{Cr}$ in organs of rats after single injection of $\mathrm{K}_{2} \mathrm{Cr}_{2} \mathrm{O}_{7}$ $(\mu \mathbf{g} / \mathbf{g})$

\begin{tabular}{crrrrrrrrrr}
$\begin{array}{c}\text { Sacrificed } \\
\text { after }\end{array}$ & Lung & Liver & Kidney & Brain & Heart & Spleen & Testis & Muscle & Hair & Blood \\
\hline 1 hour & 7.69 & 43.85 & 11.81 & 1.42 & 4.30 & 9.67 & 2.68 & 2.80 & 1.28 & 6.32 \\
3 hours & 5.43 & 11.36 & 51.90 & 2.82 & 4.15 & 8.88 & 3.47 & 1.45 & 0.67 & 5.66 \\
6 honrs & 6.34 & 9.63 & 38.17 & 1.55 & 3.46 & 8.50 & 2.57 & 1.99 & 3.97 & 7.38 \\
9 hours & 5.55 & 10.18 & 43.12 & 0.88 & 2.48 & 6.81 & 1.33 & 0.78 & 1.48 & 6.83 \\
12 hours & 4.21 & 9.72 & 43.26 & 0.70 & 2.85 & 7.06 & 0.95 & 0.69 & 0.51 & 6.25 \\
24 hours & 3.99 & 6.80 & 35.98 & 0.79 & 2.47 & 7.70 & 0.84 & 0.70 & 0.76 & 6.73 \\
2 days & 4.15 & 4.05 & 24.78 & 0.48 & 2.42 & 7.03 & 0.83 & 0.64 & 1.25 & 6.05 \\
3 days & 3.58 & 4.43 & 18.45 & 0.49 & 1.79 & 8.75 & 0.94 & 0.62 & 0.82 & 6.37 \\
4 days & 2.06 & 3.54 & 16.48 & 0.44 & 1.30 & 4.10 & 0.75 & 1.67 & 0.70 & 5.63 \\
5 days & 1.32 & 1.98 & 9.20 & 0.41 & 1.65 & 6.22 & 0.72 & 2.30 & 0.76 & 7.07 \\
10 days & 1.56 & 1.53 & 3.97 & 0.35 & 0.95 & 8.62 & 1.04 & 0.58 & 0.85 & 3.25 \\
15 days & 1.14 & 0.94 & 3.33 & 0.36 & 0.89 & 6.41 & 0.71 & 0.26 & 0.89 & 2.92 \\
20 days & 1.01 & 1.01 & 2.35 & 0.36 & 0.48 & 12.03 & 0.27 & 0.18 & 0.17 & 2.92 \\
25 days & 0.71 & 0.57 & 1.46 & 0.06 & 0.42 & 8.42 & 0.24 & 0.96 & 0.20 & 1.53 \\
30 days & 0.63 & 0.73 & 1.74 & 0.06 & 0.55 & 6.41 & 0.19 & 0.12 & 0.16 & 2.15 \\
Control & 0.09 & 0.23 & 0.15 & 0.11 & 0.16 & 0.09 & 0.12 & 0.27 & 0.31 & 0.07 \\
\hline
\end{tabular}




\section{Distribution of chromium in the organs of experimental animals}

Table 3 shows the concentration of chromium in selected organs after a single injection of $\mathrm{Cr}$ VI. The animals were sacrificed at the times indicated and the concentration of chromium in the respective organs was determined.

The concentration of chromium was highest in the liver at the beginning, followed by the kidneys. However as the experimental period increased, the highest concentration was found in the kidneys. Significant accumulation of chromium was not observed in the hair samples. Table 4 shows the distribution of chromium in the organs according to the time elapsed after the injection of $\mathrm{Cr}$ III. Significant accumulation of chromium even in the liver and the kidneys was not observed. This shows that $\mathrm{Cr}$ III was retained at the site of injection for a long period of time except for a relatively large amount excreted into the feces via the blood and bile within 24 hours. The rate of local retention of chromium was measured 24 hours after Cr VI and Cr III injection. At that time $42.4 \%$ of the total chromium administered was found in the muscle at the site of injection of $\mathrm{Cr}$ III, and another $46.3 \%$ was found in the skin in that area. This indicates that $88.7 \%$ of Cr III was still retained at the site of injection, while after the injection of $\mathrm{Cr}$ VI, $1.1 \%$ and $5.3 \%$ of chromium was found in the muscle and skin, respectively, at the site of injection.

\section{Pharmacokinetic differences between $\mathrm{Cr}$ VI and Cr III}

The concentration of chromium in the organs was followed according to the time elapsed from the single injection.

Table 4. Concentration of $\mathrm{Cr}$ in organs of rats after single injection of $\mathrm{Cr}\left(\mathrm{NO}_{3}\right)_{3}(\mu \mathrm{g} / \mathrm{g})$

\begin{tabular}{ccccccccccc}
\hline $\begin{array}{c}\text { Sacrificed } \\
\text { after }\end{array}$ & Lung & Liver & Kidney & Brain & Herat & Spleen & Testis & Muscle & Hair & Blood \\
\hline 1 hour & 0.43 & 0.37 & 1.05 & 0.32 & 0.56 & 0.17 & 0.16 & 0.11 & 1.12 & 0.99 \\
3 hours & 0.38 & 0.24 & 0.62 & 0.22 & 0.33 & 0.19 & 0.14 & 0.24 & 4.37 & 0.48 \\
6 hours & 0.23 & 0.30 & 0.62 & 0.13 & 0.15 & 0.19 & 0.16 & 0.04 & 0.59 & 0.52 \\
9 hours & 0.16 & 0.22 & 0.51 & 0.35 & 0.29 & 0.62 & 0.13 & 0.17 & 0.21 & 0.45 \\
12 hours & 0.25 & 0.22 & 0.95 & 0.14 & 0.87 & 0.24 & 0.19 & 0.36 & 0.43 & 0.41 \\
24 hours & 0.11 & 0.34 & 0.81 & 0.09 & 0.59 & 0.38 & 0.33 & 0.25 & 0.22 & 0.22 \\
2 days & 0.17 & 0.52 & 0.99 & 0.06 & 0.18 & 0.39 & 0.17 & 0.13 & 0.21 & 0.11 \\
3 days & 0.17 & 0.72 & 1.20 & 0.04 & 0.18 & 0.66 & 0.14 & 0.37 & 0.66 & 0.10 \\
4 days & 0.22 & 1.79 & 3.80 & 0.09 & 0.22 & 1.57 & 0.23 & 0.32 & 3.59 & 0.15 \\
5 days & 0.35 & 1.43 & 1.18 & 0.08 & 0.25 & 0.62 & 0.15 & 0.38 & 0.52 & 0.10 \\
10 days & 0.38 & 0.28 & 0.94 & 0.12 & 0.25 & 0.40 & 0.18 & 0.46 & 0.54 & 0.06 \\
15 days & 0.32 & 0.60 & 1.17 & 0.42 & 0.24 & 0.31 & 0.31 & 0.28 & 0.48 & 0.12 \\
20 days & 0.19 & 0.22 & 0.77 & 0.26 & 0.20 & 0.27 & 0.13 & 0.20 & 0.72 & 0.05 \\
25 days & 0.19 & 0.49 & 0.67 & 0.30 & 0.24 & 0.47 & 0.26 & 0.35 & 0.17 & 0.02 \\
30 days & 0.15 & 0.48 & 0.49 & 0.06 & 0.35 & 0.42 & 0.11 & 0.20 & 0.23 & 0.02 \\
Control & 0.09 & 0.23 & 0.15 & 0.11 & 0.16 & 0.09 & 0.12 & 0.27 & 0.31 & 0.07 \\
\hline
\end{tabular}


Table 3 shows the increase or decrease of chromium in the lung, liver, kidney, brain, heart, spleen testis, muscle, hair and blood after the administration of hexavalent chromium. It was found that a high concentration of chromium was maintained in the blood up to around the 20th day and then decreased. The peak concentration of chromium in the blood was observed on the 5th day, except for another peak that appeared in the 6-hours sample. The concentration of chromium in the other organs increased rapidly after the injection and then decreased slowly, particularly after the 10 th day.

The behavior of trivalent chromium is shown in Table 4. A marked diffcrence in the kinetics of $\mathrm{Cr}$ VI and Cr III was found in the mode of transport and accumulation in the several organs.

After the administration of $\mathrm{Cr}$ III, the amount of chromium in the blood increased rapidly within one hour, then returned to almost the normal value within 24 hours. The other organs showed no characteristic increase or decrease, though a sporadic and unpredictable increase was observed in the liver, kidney, spleen and brain.

\section{Calculation of biological half-time of hexavalent chromium}

The biological half-time was calculated from the data shown in Table 3. The following equation from the TGMA (1973) formulas was used:1)

$$
\begin{aligned}
& C=C_{0} \cdot e^{-b t} \\
& C=\text { concentration in the organ at time } t \\
& C_{0}=\text { concentration in the organ at time } 0 \\
& b=\text { elimination constant } \\
& t=\text { time } \\
& T=\frac{\operatorname{Ln} 2}{b} \\
& T=\text { biological half-time (B.H.T.) } \\
& L n 2 \text { natural logarithm of } 2=0.693
\end{aligned}
$$

The results of calculation by the least square method are shown in Figures 1 and 2 .

As has already been demonstrated in Table 4, calculation of the B.H.T. for the trivalent chromium was not possible because there was no logical increase or decrease in the amount of chromium in the respective organs. By using the rate of elimination observed in some of the organs that are shown in Table 3, however, it was possible to calculate the B.H.T. by the TGMA formula. The organs for which the formula could be adopted were the kidney, liver, heart, lung, testis, brain, and blood. It was not possible, however, to determine the B.H.T. in the spleen, muscle or hair because these specimens did not show any logical decrease or increase in the amount of chromium during the course of the experiment.

Table 5 shows the results of calculation of the B.H.T. The lung showed two components represented by two kinds of regression lines. The calculated B.H.T. 


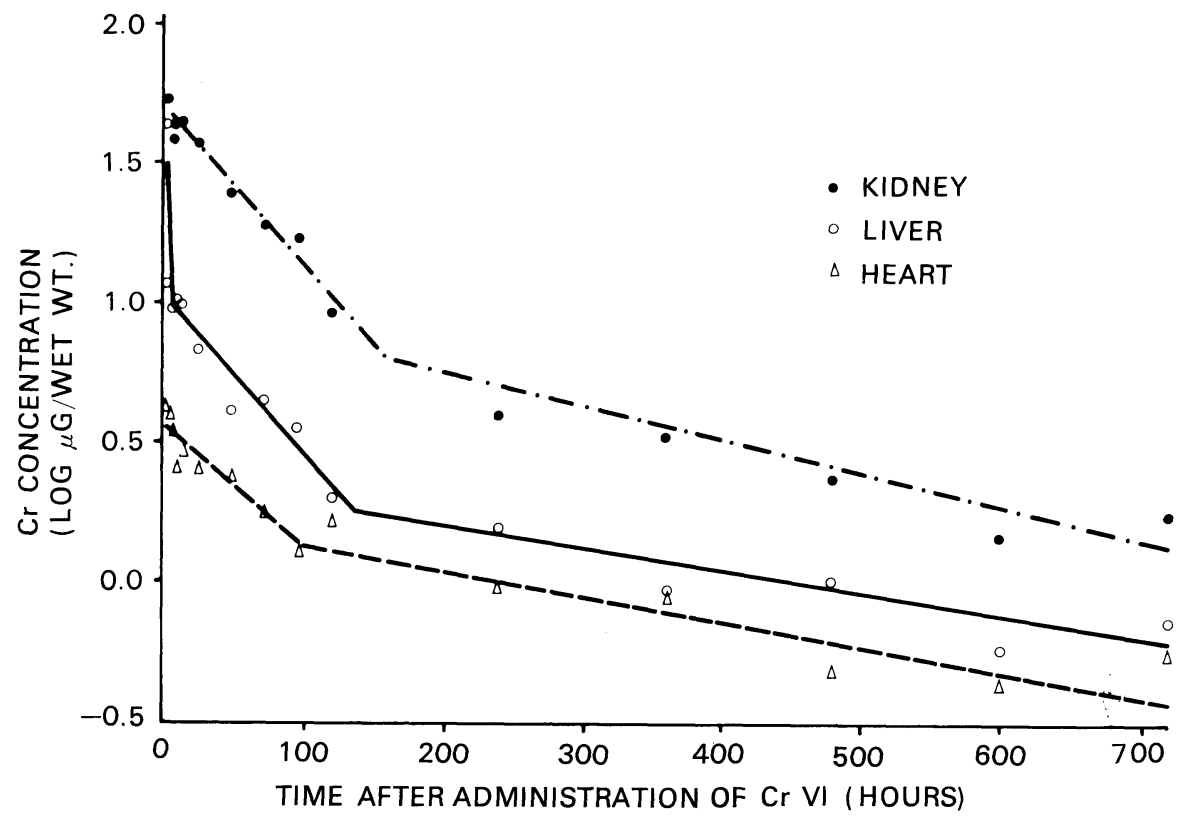

Fig. 1. Regression line found in organs of rats administered hexavalent chromium (5 mg, Cr/kg, b.w.)

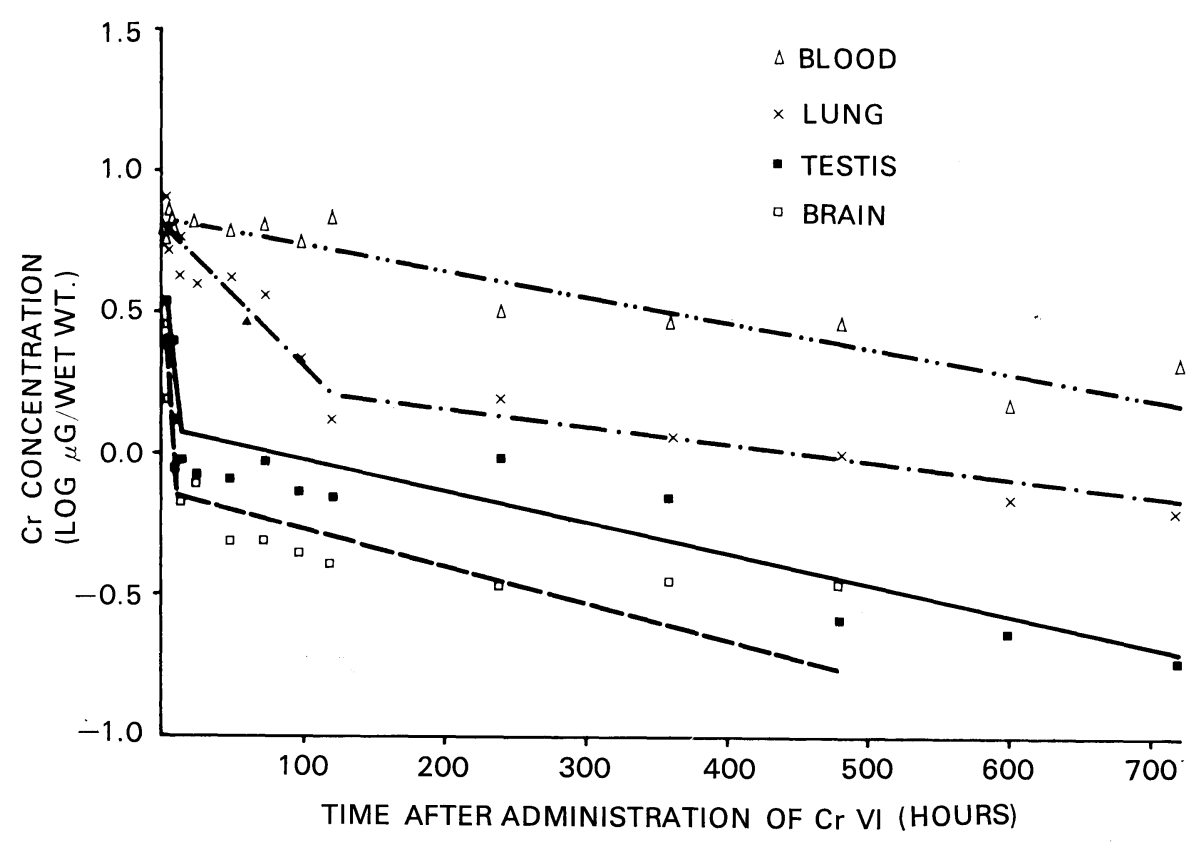

Fig. 2. Regression line found in organs of rats administered hexavalent chromium (5 mg, Cr/kg, b.w.) 
Table 5. Calculation of regression line and biological half-time (Cr VI)

\begin{tabular}{|c|c|c|c|c|c|c|}
\hline Organ & $\underset{(h}{\operatorname{Tim}}$ & $\begin{array}{l}\text { e after } \\
\text { histration } \\
\text { ours) }\end{array}$ & $\begin{array}{c}\text { Concentration } \\
\text { of } \mathrm{Cr} \\
(\log \text { of } \mu \mathrm{g} / \mathrm{g})\end{array}$ & Regression line & $\begin{array}{c}\text { Mean } \\
\text { devia- } \\
\text { tion }\end{array}$ & $\begin{array}{c}\text { Biologi- } \\
\text { cal } \\
\text { Half- } \\
\text { time } \\
\text { (B.H.T) }\end{array}$ \\
\hline \multirow[t]{2}{*}{ Lung } & 1 & $\sim 118$ & $0.792 \sim 0.207$ & $Y=0.7968-0.0050 X$ & 0.0016 & 60.173 \\
\hline & 118 & $\sim 720$ & $0.207 \sim-0.155$ & $Y=0.2774-0.0006 X$ & 0.0210 & 501.610 \\
\hline \multirow[t]{3}{*}{ Liver } & 1 & $\sim 5.31$ & $1.513 \sim 0.983$ & $Y=1.6363-0.1229 X$ & -0.0030 & 2.449 \\
\hline & 5.31 & $\sim 133.9$ & $0.983 \sim 0.250$ & $Y=1.0135-0.0057 X$ & -0.0010 & 52.805 \\
\hline & 133.9 & $\sim 720$ & $0.250 \sim-0.219$ & $Y=0.3573-0.0008 X$ & 0.0080 & 376.180 \\
\hline \multirow[t]{2}{*}{ Kidney } & 3 & $\sim 156.3$ & $1.669 \sim 0.796$ & $Y=1.6862-0.0057 X$ & -0.0013 & 52.802 \\
\hline & 156.3 & $\sim 720$ & $0.796 \sim 0.119$ & $Y=0.9830-0.0012 X$ & 0.0022 & 250.798 \\
\hline Brain & 3 & $\sim 11.372$ & $0.416 \sim-0.159$ & $Y=0.6225-0.0687 X$ & 0.0003 & 4.381 \\
\hline $\begin{array}{l}\text { (Cerebrum and } \\
\text { cerebellum) }\end{array}$ & \multicolumn{2}{|c|}{$11.372 \sim 480$} & $-0.159 \sim-0.768$ & $Y=-0.1440-0.0013 X$ & -0.0230 & 231.518 \\
\hline \multirow[t]{2}{*}{ Heart } & 1 & $\sim 93.417$ & $0.550 \sim-0.135$ & $Y=0.5549-0.0045 X$ & 0.0010 & 66.877 \\
\hline & \multicolumn{2}{|c|}{$93.417 \sim 720$} & $0.135 \sim-0.429$ & $Y=0.2186-0.0009 X$ & -0.0013 & 334.422 \\
\hline \multirow[t]{2}{*}{ Testis } & 3 & $\sim 11.464$ & $0.563 \sim-0.007$ & $Y=0.7600-0.0657 X$ & 0.0045 & 4.581 \\
\hline & \multicolumn{2}{|c|}{$11.464 \sim 720$} & $0.007 \sim-0.702$ & $Y=0.0183-0.0010 X$ & 0.0022 & 300.854 \\
\hline Blood & 1 & $\sim 720$ & $0.826 \sim-0.179$ & $Y=0.8265-0.0009 X$ & 0.0091 & 334.407 \\
\hline
\end{tabular}

was 60.2 hours (2.5 days) and 501.6 hours (20.9 days). The liver showed three components, 2.4 hours, 52.8 hours and 376.2 hours (15.7 days); the kidney had two components, 52.8 hours and 250.8 hours (10.5 days); the brain also showed two components, 4.4 hours and 231.52 hours (9.6 days); the heart showed two components, 66.9 hours and 334.42 hours (13.9 days); the testis also showed two components, 4.58 hours and 300.9 hours (12.5 days); and the blood had only one component, 334.4 hours (13.9 days). All of the organs selected for calculation except the blood and liver had two components. The complexity of the pharmacokinetics of hexavalent chromium compounds expressed by multi-components is indicated by the variability in the structure and the valency of the chromium compounds present in the biological medium.

\section{Discussion}

A study of the biological half-time of a hexavalent chromium compound was carried out. There are a number of articles on the toxic effects of chromium compounds determined both by animal experiments and by observations ${ }^{2-5}$ ) in humans, and it is generally accepted fact that the toxic effect of hexavalent chromium is stronger than that of the trivalent chromium compound ${ }^{6)}$. Hexavalent chromium is also a strong oxidizing agent and is able to penetrate the cell membrane. In contrast, trivalent chromium is relatively inactive, is unable to penetrate cell membranes and rapidly reacts with proteins and other ligands, becoming 
firmly attached. It is well known that hexavalent chromium in the blood can penetrate into the red blood cells and then it is reduced to the trivalent form firmly attached to the hemoglobin ${ }^{7-9)}$. This fraction of the chromium is excreted through the reticuloendothelial system as the red blood cells disintegrate.

It is shown in Table 3 that the amount of chromium in the spleen after the administration of the hexavalent chromium compound increased with the length of the experimental period and that a high concentration of $\mathrm{Cr}$ was maintained until around the 20th day.

As hexavalent chromium is reduced instantly to the trivalent chromium and retained for a long period of time in the red blood cells firmly bound to hemoglobin, the red blood cells will be decomposed one by one. Thus a high concentration of chromium in the spleen, as shown in Table 3, was maintained until around the 20th day when the proportion of decomposed red blood cells is presumed to have reached a maximum.

After the 20th day, the proportion of chromium-containing red blood cells decreased rather rapidly, presumably as each red blood cell died, in addition to the destruction of cells due to the artificial injury caused by the adverse effects of Cr VI on the cell membrane.

Mertz et al. ${ }^{10,11)}$ also carried out an experimental study on the biological halftime of trivalent chromium in rats after intravenous administration. They found that there are three main components, with half-lives of $0.5,5.9$ and 83.4 days. They stated that the behavior of chromium chloride was not influenced by the dose or the nutritional condition of the experimental animals; hence it might not be representative of the biologically important fraction of chromium, which may be only a small part of the total. However in their experiment, the trivalent chromium compound was administered by intravenous injection. Therefore the pharmacokinetic behavior will not be comparable with that after subcutaneous administration. The behavior of the chromium in a biological medium depends heavily on its chemical form, the route of entry and the amount of chromium administered. In many studies amounts far beyond the physiologic range have been used. It is therefore not completely clear whether the great affinity of the reticuloendothelial system, i.e., liver, spleen and bone marrow, for chromium is a physiologic phenomenon or an expression of an overload.

(A part of this article was presented at the CHROMATES SYMPOSIUM 80, Sept. 16-18, Rockville, Md., U.S.A., 1980)

\section{REFERENCES}

1) TGMA. (1976). Effects and Dose-response Relationships of Toxic Metals (Edited by G.F. Nordberg), 23. Elsevier Scientific Publishing Co. (TGMA; Task Group on Metal Accumulation 1973).

2) U.S.Dept. Health, Education and Welfare. (1973). Criteria for a recommended standard, Occupational Exposure to Chromic Acid. 18, 35. (NIOSH) 
3) Symavoryan, P.S. (1967). Effect of hexavalent chromium on concentration and dilusion capacity of dog kidney, Chem. Abstr. 66, 74481s.

4) Schroeder, H.A., J.J. Balassa. (1965). Influence of chromium, cadmium, and lead on rat aortic lipids and circulating cholesterol, Am. J. physiol. 209, 433.

5) Schroeder, H.A., J.J. Balassa and I.H. Tipton. (1962). Abnormal trace metals in manchromium, J. Chron. Dis. 15, 941.

6) Documentation of the threshold limit values for substances in workroom air. (1971). American Conference of Governmenual Industrial Hygienists, Chromium. Third Edition. 56.

7) S.B. Barker. (1951). Mechanism of action of the thyroid hormone, Physiol. Rev. 31, 205.

8) S.A. Berson and R.S. Yalow. (1954). The distribution of iodine-labeled human serum albumin introduced into ascitic fluid: analysis of the kinetics of a three-compartment catenary transfer system in man and speculations on possible sites of degradation, $J$. Clin. Invest. 33, 377.

9) J.R. Bronk. (1960). The influence of thyroxine and related compounds on oxidative rate and efficiency of phosphorylation in liver mitochondria and submitochondrial particles, Ann. N.Y. Acad. Sci. 86, 494.

10) Mertz, W.E.E., Roginski and R.C. Reba. (1965). Biological activity and fate of trace quantities of intravenous chromium III in the rat, Am. J. Physiol, 209, 489.

11) Mertz, W. and E.F. Roginski. (1971). Chromium metabolism, the glucose tolerance factor. W. Mertz and W.E. Cornatzer, Eds.: Newer trace Element in Nutrition, New York, Marcel Dekker. 123. 